\title{
Key stakeholders' perspectives towards UK new-build housing defects
}

Article

Accepted Version

Hopkin, T., Lu, S.-L., Rogers, P. and Sexton, M. (2017) Key stakeholders' perspectives towards UK new-build housing defects. International Journal of Building Pathology and Adaptation, 35 (2). pp. 110-123. ISSN 2398-4708 doi: https://doi.org/10.1108/IJBPA-06-2016-0012 Available at https://centaur.reading.ac.uk/69811/

It is advisable to refer to the publisher's version if you intend to cite from the work. See Guidance on citing.

To link to this article DOI: http://dx.doi.org/10.1108/IJBPA-06-2016-0012

Publisher: Emerald

All outputs in CentAUR are protected by Intellectual Property Rights law, including copyright law. Copyright and IPR is retained by the creators or other copyright holders. Terms and conditions for use of this material are defined in the End User Agreement.

\section{www.reading.ac.uk/centaur}

\section{CentAUR}

Central Archive at the University of Reading 
Reading's research outputs online 


\title{
Key stakeholders' perspectives towards UK new-build housing defects
}

\begin{abstract}
:
Purpose: Research on housing defects has limited its enquiry to the classifications of defects, potential impact of defects, and their detection and remediation during construction and the builder's liability period, without considering the warranty period. This paper aims to better understand which impacts of defects are perceived as important by the key stakeholders involved in their detection and remediation over the construction, builder's liability and insurer's warranty periods.

Design/methodology/approach: The questionnaire survey approach was used. The questionnaire distribution list was drawn from the UK's largest warranty provider and approved inspector's records. The questionnaire was distributed to 2003 people, receiving 292 responses, a response rate of $15 \%$. Findings: This research challenges the assertion that the house building industry (i.e. house builders, building inspectors and warranty providers) is predominantly cost focused and finds that the potential impact of defects on home occupants are their primary concern. In contrast, the home occupants' appear solely focused on the disruption defects caused on their daily lives and perceive a lack customer focus in the house building industry. Originality/value: This study provides empirical evidence of the contrasting view of the house building industry and home occupants with respect to the prioritisation of the impacts of defects. Further, this research offers house builders an alternative approach to determine which defects should be targeted for reduction purposes which may lead to improved levels of customer satisfaction.
\end{abstract}

Keywords: Defects, New-build Housing, Warranty

Paper type: Research Paper

\section{Introduction}

In the United Kingdom (UK) there is a significant shortage of homes, exacerbated by a prolonged under supply of new housing (Parliament, 2016). The UK Government introduced a number of incentives to increase the new-build housing supply. For example, the Housing Infrastructure Fund is planned to allocate $£ 1.4 \mathrm{~b}$ to provide 40,000 new affordable homes and another $£ 1.7 \mathrm{~b}$ to speed up the construction of new homes on public sector land (HM Treasury, 2016). House builders have responded to the pent up demand and policy incentives by significantly up-scaling supply, with a 78\% increase in housing starts for 2015 compared to the 2008 downturn (DCLG, 2016). There is evidence that the rapid upscaling of supply has had a negative impact on build quality, causing an increase in defects (Hopkin et al., 2016). There is strong historical evidence that a step-change in housing production causes supply chains and skills to become over-stretched due to excessive workload (Sommerville et al., 2004). There are indications of over-stretching in the current uplift in supply, with the UK house building sector reporting acute materials, skills and workforce shortages (CITB, 2015). Further evidence of overstretching is in the increased volume of new housing defects. The Home Builders Federation survey, for example, shows that in $2016,93 \%$ of home occupants reported defects within their new-build house, the highest level since 2010 (HBF, 2016).

The extant literature has long argued for a reduction in defects in new homes to both benefit the house building industry and improve home occupants' satisfaction (Barker, 2004; Auchterlounie, 2009). The literature however tends to limit its enquiry to the classification of defects. Although the classification literature provides valuable detail as to the most prevalent type of defects occurring within new homes, it can be prone to assuming all defects have the same level of importance and is unable to guide industry on which defects are more important (Somerville, 2007). By differentiating between individual defects 
[To cite this article: Tony Hopkin, Shu-Ling Lu, Phil Rogers \& Martin Sexton (2017): Key stakeholders' perspectives towards UK new-build housing defects, International Journal of Building Pathology and Adaptation, DOI: 10.1108/IJBPA-06-2016-0012]

and identifying which aspects are important to those who experience them, the literature could provide more specific guidance. Further, previous studies typically concentrate on defect that occur within the construction phase of homes or within the first two years post-completion without considering the entire warranty period. By focussing predominantly on defects during construction or the first two years postcompletion, the extant literature tends to only explore the involvement of the builder, home occupant, and/or building inspector in defects detection and remediation without considering the important role the warranty provider plays during the warranty period. The argument to this point identifies that researching defects throughout the three phases and exploring the impact of defects in new homes would offer new insight and understanding about; (a) the range of stakeholders who experience them; (b) the impact defects cause; and, (c) the house building industry's capability to determine what is important and what should be the specific areas of focus for defect reduction.

Questionnaire results provide empirical evidence in respect of which impacts of defects are perceived as important to those involved in their detection and remediation. The results challenge the assertion that the house building industry is predominantly cost-focused and reveal that the house building industry stakeholders (house builders, warranty providers and building inspectors) view the home occupant related impacts of safety and disruption as the most important. In contrast, the home occupants appear solely concerned with the effects defects have directly on them, such as the disruption defects cause, and the safety concerns defects pose; and, perceive a lack of customer focus in the house building industry.

\section{Overview of defect detection and remediation within UK new-build}

\section{housing and key stakeholders involved}

There is no universal definition of 'defects', but differing 'defect' descriptions appear to describe the same phenomenon, i.e. imperfections in buildings (Macarulla et al., 2013). Indeed, the term 'defect' in new housing has been used interchangeably with labels such as 'snags' (Sommerville and McCosh, 2006) and 'non-compliance' (Baiche et al., 2006). For this paper, a defect is understood as 'the breach of any mandatory National House Building Council (NHBC) Requirement by the Builder or anyone employed by or acting for the Builder' (NHBC, 2012:3). The NHBC's definition has been adopted because over $80 \%$ of new homes in the UK need to be built in accordance with NHBC standards (which include Building Regulations) to receive warranty cover (NHBC, 2015). The NHBC is the UK's leading standard-setting body, approved inspector and provider of warranties for new homes. The NHBC warranty typically offers 10 years of post-completion cover (in addition to certain cover before completion) and is split into two sections: cover during the first two years (builder's liability period) and cover during years 3-10 (NHBC, 2012). The warranty is a tripartite agreement between the house builder (HB), home occupant (HO) and warranty provider (WP). Under the terms of the warranty the $\mathrm{HB}$ is responsible for rectifying any breach of the requirements within the builder's liability period and any breach that may result in a warranty claim in years 3-10 will ultimately affect the HB's premium rating (NHBC, 2011). A new home warranty plays an important role within the detection and remediation of UK new-build housing defects for two reasons. First, mortgage lenders will generally only lend on a new-build house when the property is covered by a warranty (CIC, 2010). Second, the warranty offers protection for HOs and redress in respect of defects because new homes are exempt from the Sale of Goods Act (Sommerville and McCosh, 2006) and the contractual arrangements employed whereby the HB is the "employer" and the work is subcontracted out (Craig, 2007) means that HOs have no redress under the construction contract. 
[To cite this article: Tony Hopkin, Shu-Ling Lu, Phil Rogers \& Martin Sexton (2017): Key stakeholders' perspectives towards UK new-build housing defects, International Journal of Building Pathology and Adaptation, DOI: 10.1108/IJBPA-06-2016-0012]

The detection and remediation of UK new-build housing defects can be grouped into three phases: the construction phase, the two year builder's liability period and the eight year warranty period (these three phases are followed by the majority of the UK's new home warranty providers, including NHBC, Premier Guarantee, LABC Warranty, and Checkmate) (see Figure I). Within the three phases, four key stakeholders were identified: HOs, HBs, WPs, and building inspectors (BIs).

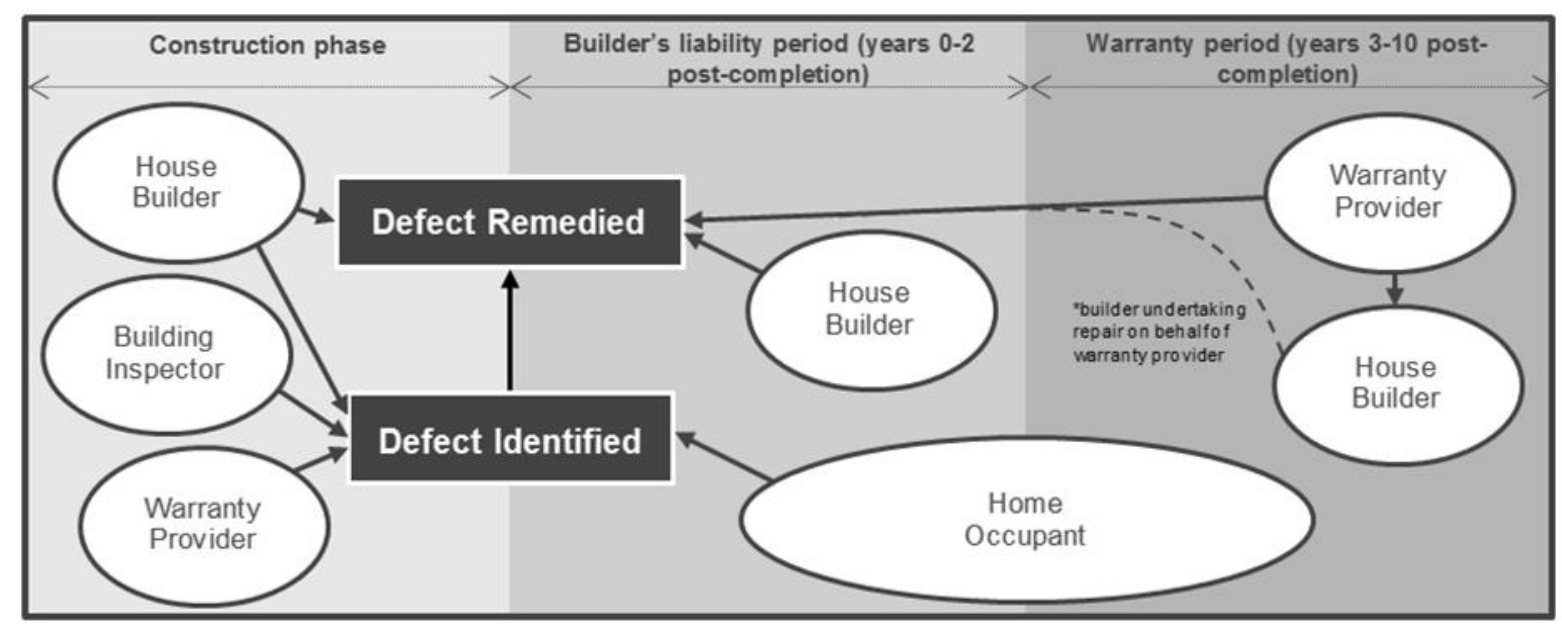

Figure I: Defect detection and rectification within UK new-build housing

During a new home's construction, an inspection procedure involving examination of work on-site takes place to assess whether compliance with the Building Regulations has been achieved (Wilson and Rhodes, 2016). The inspection procedure can be undertaken by either a BI from the local authority or an independent approved inspector (e.g. MDIS, NHBC) (CIC, 2014). During construction, BIs frequently identify defects and produce checklists that require correction by the $\mathrm{HB}$ (Baiche et al., 2006). As work progresses on-site the HB also undertakes quality inspections and if defects are identified the HB will rectify them (Sommerville et al., 2004). For new homes covered by a warranty, additional inspections are carried out by the WP (e.g. Premier Guarantee, NHBC) at key stages (e.g. foundations, superstructure) to ensure compliance with the WP's standards (Auchterlounie, 2009). If any deviations are found the HB is required to rectify them to receive the warranty.

During the builder's liability period (years 0-2 post-completion), the house building industry undertakes a snagging process (identifying defects) which is heavily reliant on the HO to report any defects back to the HB (Sommerville et al., 2004). The HB is required to rectify defects under their liability, which is a requirement under the warranty (Premier Guarantee, 2013; NHBC, 2012).

Beyond the first two years, most new homes are subject to a warranty period of a further eight years. The WP covers building defects during the warranty period (NHBC, 2012; Premier Guarantee, 2013). During this period, the $\mathrm{HO}$ is required to notify the WP of any defects, and offer the WP an opportunity to inspect his/her home. Upon acceptance of a valid claim, the WP will make the necessary arrangements to have the defect remedied by either themselves, or offer the $\mathrm{HB}$ the opportunity to rectify the defect to protect their renewal fee from increase (NHBC, $2012 \& 2011$ ).

\section{Research problem}

The previous section has indicated that there are three specific stages in a new-build house's life where defects are recorded: the construction phase, the builder's liability period and the warranty period. Research on housing defects tends to focus on the construction phase (e.g. Atkinson, 2002) and the 
[To cite this article: Tony Hopkin, Shu-Ling Lu, Phil Rogers \& Martin Sexton (2017): Key stakeholders' perspectives towards UK new-build housing defects, International Journal of Building Pathology and Adaptation, DOI: 10.1108/IJBPA-06-2016-0012]

builder's liability period (e.g. Craig, 2007), yet the occurrence of defects within new-build houses is not limited to these two stages. Within the respective individual stages researchers tend to adopt a similar approach of classifying defects based upon the characteristics defects display, where they occur and their causes to highlight the frequency of these aspects (e.g. Georgiou et al. 1999; Mills et al., 2009). What is also evident is that defects detected in each of the three stages are different. During construction, defects tend to be positioned around Building Regulation contraventions, as identified by the BI. Baiche et al. (2006), for example, indicate that the most common Building Regulation contraventions include radon protection, and inadequate thermal insulation. During the builder's liability period, defects typically relate to 'aesthetics' as identified by the HO. Some support for the aesthetics idea is Craig's (2007) finding that making good, paint, cleaning, and sealant are the prevalent 'snags' in UK new homes. Within the warranty period there are indications of defects associated with building fabric and structure being reported to the WP. Mills et al. (2009), for example, stress that the most prominent sources of warranty claims in Australia include foundation failures, roof leaks, and external water penetration. By focussing predominantly on defects during construction or the builder's liability period, the UK scholarship tends to only explore the involvement of the $\mathrm{HB}, \mathrm{HO}$, and/or BI in defects detection and remediation without considering the important role of the WP plays during the warranty period. This view is consistent with Forcada et al. (2016) who suggest the need to consider defects during construction, during the builder's liability period, and defects beyond the builder's liability period.

Furthermore, prevailing research can be prone to assuming that all defects have the same level of importance (focusing on frequency alone) (e.g. Craig, 2007; Sommerville and McCosh, 2006) and there is disagreement by the commentators over which types of defects the house building industry needs to focus on (when considering defects on any basis other than frequency alone). Baiche et al. (2006) and Ilozor et al. (2004), for example, argue that the emphasis should be placed upon reducing individual defects in areas deemed detrimental to the health and safety of HOs, Georgiou et al. (1999), for instance, propose that individual defects with high associated costs should be considered high priority. This view resonates with Sommerville et al.'s (2004) argument that only high expenditure on defects will motivate HBs to reduce them. Davey et al. (2006) acknowledge that reducing defects could save money, but further assert that disruption caused by remediation is an important consideration. Sommerville (2007) argues that we have the situation in housing defect research where researchers are able to identify the issues causing defects and the size of the problem, but are unable to determine whether the defect, or any particular aspect of it, is important or not. The NAO (2007) suggests that practitioners need to consider the volume of defects as well as the impact defects have. The aim of this research therefore is to gain insight into which impacts of defects are perceived as important by the key stakeholders involved in their detection and remediation from construction on-site until the end of the warranty period. In order to do so, the potential impacts of defects need to be examined first.

\section{Potential impact of defects}

A review of existing construction defect literature has identified a number of common aspects which have the potential to cause negative impacts to a variety of stakeholders involved with construction projects, including: health and safety (H\&S) implications (Baiche et al., 2006; Smith et al., 2013), cost (Love and Li, 2000; Rosenfeld, 2009), and general disruption (Davey et al., 2006; BEC, 1991). Each of these aspects are discussed below. 


\section{$H \& S$ implications}

The reduction of defects has the potential to improve construction site H\&S and reduce danger for site workers (Macarulla et al., 2013). Reducing defects can also decrease H\&S concerns post-completion. More specifically, reducing defects that contravene Building Regulations (as opposed to more aesthetic snagging issues) can reduce potential danger to HOs. Building Regulations compliance certifies that reasonable standards of $\mathrm{H} \& \mathrm{~S}$ are ensured for building users (Baiche et al., 2006).

\section{Cost implications}

Remediation of defects occurring during the construction stage and the builder's liability period is suggested to cost the builder on average between $2.3 \%$ and $9.4 \%$ of the production cost (Josephson and Hammarlund, 1999; Love and Li, 2000). During the warranty period, the cost of defect remediation in Australia is argued to be circa 4\% of the contract value (Mills et al., 2009). In 2015 in the UK the NHBC spent $£ 87 \mathrm{~m}$ on resolving warranty claims (NHBC, 2015). The specific cost of defects can be grouped into five categories: the cost of investigating defects (for HBs and WPs), the cost of repairs (for HBs and WPs), effect of warranty repairs on HBs, the cost for resolving complaints resulting from defects (for HBs and WPs), and the cost of regulatory non-compliance (for HBs, BIs, and WPs).

Investigation costs: defects can be investigated by the HB's staff, by an external party such as a WP, or in some cases by both parties (Rosenfeld, 2009; NHBC, 2012). During construction and the builder's liability period the HB will investigate defects that occur (Sommerville et al., 2004). During the warranty period the WP will undertake the investigations. The WP can potentially request the HB to assist during the investigations on warranty claims. If the $\mathrm{HB}$ fails to assist the WP during the investigations the WP can recover the investigation cost directly from the HB (NHBC, 2011).

Repair costs: three specific costs have a large bearing on the overall costs of repairs (Mills et al., 2009; Rosenfeld, 2009): the cost of labour, materials, and equipment. On average, it costs $£ 100$ for an operative to repair a defect in the UK (HouseMark, 2012:8). However, it should be noted that different defects cost varying sums to remedy; for instance, remediation of external water penetration is generally more costly than plumbing (Mills et al., 2009). The repair costs during the builder's liability period are typically incurred by the HB. The cost of warranty repairs are also identified as a potential cost (Rosenfeld, 2009) and are typically incurred by one of two parties: the WP or the HB. During the warranty period the WP is liable for the repair. Upon acceptance of a valid claim, the WP will make the necessary arrangements to have the defect remedied (NHBC, 2012). Studies show that the warranty provider spends large sums of money rectifying defects (Mills et al., 2009).

Effect of warranty repairs on HB: due to costs incurred on warranty repairs, WPs keep records of claims history where the WP has undertaken the repair in order to calculate the HB's renewal fees. However in a number of cases the $\mathrm{HB}$ will choose to undertake repairs on warranty claims themselves in order to protect their renewal fee from increase (NHBC, 2011).

The cost of complaints: defects can potentially cause complaints from the HOs (Sommerville et al., 2004). Handling complaints resulting from defects has the potential to cause additional costs, including legal costs and compensation. Furthermore, handing complaints also consume HB's time as they are required to urgently deal with complaining HOs instead of undertaking their daily activities (Rosenfeld, 2009). WPs are not immune to customer complaints either. For the 2013 financial year the Financial Ombudsman Service (FOS, 2013) reported a 60\% increase in HOs complaining about a home WP's service. 
The cost of regulatory non-compliance: during construction, a BI must take all reasonable steps to ensure that the Building Regulations requirements have been met (DCLG, 2012). If BIs fail to fulfil their contractual obligations (when acting as an approved inspector) the client can sue them for breach of contract (ACAI, 2013). When undertaking construction work the primary responsibility for achieving regulatory compliance, however, remains with the HB (HMSO, 1984). Under the Building Act (HMSO, 1984) if a person carrying out building work contravenes the Building Regulations, he/she may be taken to the magistrates' court and ordered to pay a fine for the contravention. In specific circumstances, under a new build warranty the WP will provide cover for defects that contravene Building Regulations where they present a danger to the H\&S of the HO (NHBC, 2012).

\section{Disruption implications}

New-build housing defects generally cause disruption to both HOs and HBs (Davey et al., 2006). Three specific aspects are identified below.

Disruption to the HB's construction programme: defects occurring during the construction process can cause disruption to the HB's construction programme and remediation of defects has the potential to cause delays in handover (Sommerville et al., 2004). The disruption to the HB is typically through resource usage. For example, site management may be required to investigate the causes of defects that arise on-site while labour and equipment may be deployed to remedy defects instead of undertaking the programmed work (Rosenfeld, 2009).

Disruption to the $H B$ in arranging trades to return: handling post-completion defects has the potential to cause disruption to a HB (Rosenfeld, 2009). Disruption to HBs can include time spent travelling to investigate and remediate defects, and having to arrange for trades to return to properties to undertake repairs (Davey et al., 2006).

Disruption to $\mathrm{HO}$ in needing to allow trades to return: post-completion defects are argued to cause disruption to HOs by way of operatives having to return to, and be granted access to, their homes (Davey et al., 2006).

\section{Research method}

The questionnaire survey approach was adopted for this research to gain insight into which impacts of defects are perceived as important by the key stakeholders involved in their detection and remediation. The questionnaire distribution list was drawn from NHBC's records (see the 'overview of defect detection' section for the rationale for focusing on NHBC). The researchers were given controlled access to probe NHBC datasets, including a list of registered builders (HBs), a list of their warranty staff (WPs), a list of their building inspectors (BIs), and details of home occupants (HOs) who had previously had defects rectified under their warranty.

The questionnaire contained 15 closed and three open questions. 15 closed questions were drawn from the 'potential impact of defects' literature review above, and sought to explore the respondents' views around the H\&S implications of defects, the various costs associated, and the potential disruption caused. The three open questions were included to explore any additional potential impacts of defects that were not identified in the prevailing literature and reasons behind selected priorities. The questionnaire was piloted to test for clarity and usability before the main survey was carried out. The 
[To cite this article: Tony Hopkin, Shu-Ling Lu, Phil Rogers \& Martin Sexton (2017): Key stakeholders' perspectives towards UK new-build housing defects, International Journal of Building Pathology and Adaptation, DOI: 10.1108/IJBPA-06-2016-0012]

survey targeted the four key stakeholders (HOs, HBs, WPs, and BIs) involved in detecting and rectifying defects in new homes identified in the literature. The survey asked the respondents to prioritise the pre-determined impacts of defects on a scale of 'not a priority', 'low priority', 'medium priority', 'high priority' to 'essential priority'. The survey outlined the adopted NHBC definition of defects described in the 'overview of defect detection' section: a definition that all the stakeholders were familiar with.

The survey was distributed in May 2015 through a web link with a covering email which set out the purpose of the survey as well as research ethics safeguards. The survey was distributed to 2003 people drawn from the NHBC's database, including 817 of the 2983 HOs who have had a defect rectified under their warranty during the 2014 financial year; 161 WP's staff, 209 BIs; and, 816 of the 2892 active HBs on the NHBC's register. The duration of the survey was one month with follow-up email reminders. The overall response rate was $15 \%$ with a total of 292 responses. The survey received 51 responses from HBs, 54 responses from WP's staff, 44 responses from BIs and 143 responses from HOs.

As the questionnaire sought to order people's level of priority (from categories) with regard to the potential impact of defects, the questionnaire design produced an 'ordinal' level of measurement (Rosenthal, 2012) in which it was not possible to quantify the size of the gap between the categories or determine if the sizes were equal (as with many Likert-type surveys). Often researchers will ignore ordinality and numbers such as 1,2,3, representing the ordered categories will be treated as numbers having metric properties, a procedure which is incorrect (Joreskog and Moustaki, 2001). The ordinal data was analysed by calculating the percentage of each of the five categories (e.g. essential) within a total number of a particular set of stakeholders (e.g. HBs) for the individual impacts of defects. The results were displayed using diverging stacked bar charts (Heiberger and Robbins, 2014).

\section{Key results}

This section explores the key stakeholders' views on the impact of defects on H\&S, followed by cost and disruption.

\section{Health and safety}

The analysis of the impact of defect on 'H\&S' (figure II) revealed that all of the house building industry stakeholders (HBs, WPs, and BIs) shared a general belief that both site worker and HO H\&S are important. However, the house building industry stakeholders deemed the HO H\&S aspect as more important than site workers. The HBs, WPs and BIs perceived HOs H\&S to be an 'essential priority' $(71 \%, 50 \%$, and $66 \%)$ and a 'high priority' (22\%, 41\%, and 25\%). Conversely, the house building industry stakeholders (HBs, WPs, BIs) deemed site worker H\&S an 'essential priority' $(67 \%, 41 \%$, and $39 \%)$ and a 'high priority' $(25 \%, 39 \%$, and $16 \%)$. In stark contrast, the HOs saw their own H\&S as their highest priority overall, deeming it an 'essential priority' (42\%) and a 'high priority' (26\%). The HOs deemed site worker H\&S significantly lower than their own, considering it to be 'not a priority' (27\%) and a 'low priority' (23\%). There are indications that the HOs' H\&S self-prioritisation was driven by the perception that the house building industry does not consider HO safety with the constructed home, as stated by one $\mathrm{HO}$ “....the builder's idea of a new house is one of astonishingly poor condition with numerous short-cuts and non-compliance to building reg[ulation]s...” (HO1). 

perspectives towards UK new-build housing defects, International Journal of Building Pathology and Adaptation, DOI: 10.1108/IJBPA-06-2016-0012]

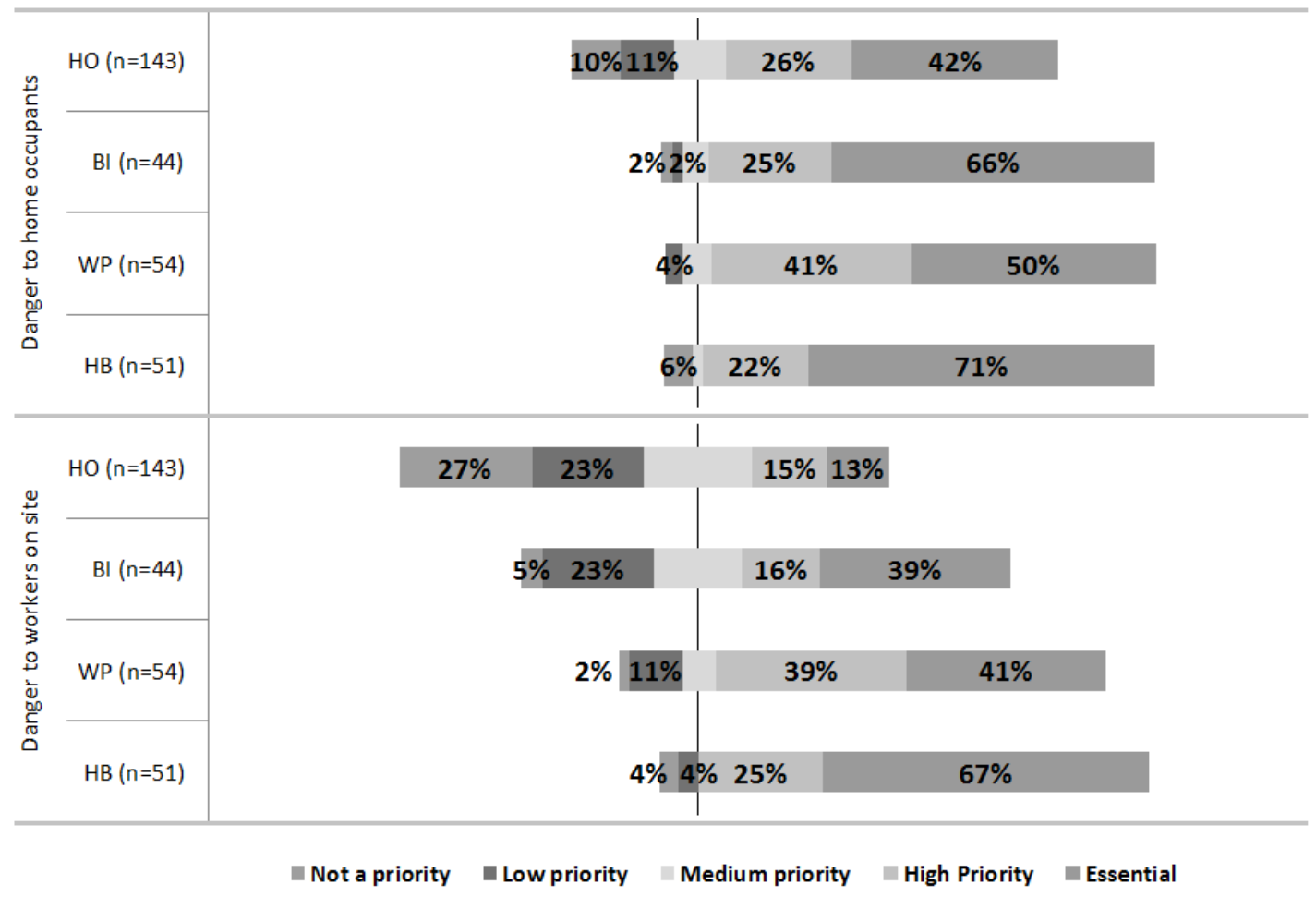

Figure II: Impact of defects on $H \& S$ priority analysis

\section{Cost}

Moving onto 'cost' (figure III), the HOs generally voted all costs as unimportant, i.e. 'not a priority' and 'low priority' (between $61 \%$ and $70 \%$ ) as none of the costs directly affected them. The HOs selffocus in relation to cost appeared to stem from the belief that the house building industry is generally financially motivated as opposed to being customer motivated. One $\mathrm{HO}$ argued that “... builders are increasingly turning to cheap low skilled workforce and materials looking for fast buck. They need to get back to the stage where they can be proud of what they produce..." (HO2).

In contrast to the HOs, the BIs, WPs and HBs had a varied cost prioritisation. The BIs appeared to generally view cost as a higher priority than the WPs and HBs. However, the BIs were clear that costs that either directly affected them or resulted from their errors were most important. The BIs voted both approved inspector fines for breach of contract as 'essential' and 'high' priorities (19\% and 33\%); and, any warranty claims resulting from Building Regulation non-compliance as an 'essential priority' (51\%) and 'high priority' (30\%). In a similar vein to the BIs, the WPs considered their own costs as generally more important. One interesting result was that the WPs deemed their cost for resolving complaints as the most important cost impact, deeming it a 'high priority' (48\%) and an 'essential priority' (15\%). The WPs, however, had little sympathy for any complaints against the HB, voting builder complaint costs as a 'low priority' (32\%) and 'not a priority' (19\%). In contrast to the BIs and WPs, the HBs showed a less bias view of cost, generally considering the cost they incur to be a similar priority to the costs the other stakeholders incur. The HBs general 'reduced' cost focus was summed up by one HB who commented that "...I do not see the issue of cost being a reason not to attend to a defect..." (HB1). Despite the general rounded view of cost, one interesting result came in relation the builder's fines for regulatory non-compliance which was deemed by the HBs as the highest cost priority, with $82 \%$ of respondents seeing it as either a 'high' or 'essential' priority. 
[To cite this article: Tony Hopkin, Shu-Ling Lu, Phil Rogers \& Martin Sexton (2017): Key stakeholders' perspectives towards UK new-build housing defects, International Journal of Building Pathology and Adaptation, DOI: 10.1108/IJBPA-06-2016-0012]

\section{Disruption}

In relation to 'disruption' (figure IV), the HBs, WPs, and BIs appeared to show a HO focus and voted disruption to HOs as the most important disruption impact, voting it as 'essential' (32\%, 19\%, and 37\%) and 'high priority' (50\%, 52\% and 44\%). This high prioritisation of HOs was stressed by one HB who stated that "...we try to look after the interests of our customer ensuring there is no risk to health and safety, disruption or cost to our customer..." (HB2). Interestingly the house building industry key stakeholders voted HO disruption higher than the HOs themselves. The HOs still deemed their own disruption as one of the most important impacts overall, seeing it as 'essential' (35\%) and 'high priority' (34\%). The HOs high prioritisation of their disruption came in relation to post-completion defects requiring a repair. HOs believed that as the purchaser of the new home, when something has gone wrong they should be the main priority. This main priority requirement was evident in three HOs who commented that “...if the builder's construction is sub-standard, resulting in a successful claim, then the only priority is the householder...” (HO3); “...as a house buyer, if the building work was not completed properly in the first place, the builders/warranty provider must accept full responsibility to ensure it is rectified as soon as possible..." (HO4); and, "...the most import[ant] consideration for me is knowing that the repair will be carried out speedily, professionally and with minimum disruption ..." (HO5). There was further evidence of HOs' being dissatisfied with inadequate remediation of defects, requiring return visits and causing additional disruption. The additional HO disruption was captured by one HOs who stated that "...the work carried out by the work men was not to a good standard and [they] had to come back a few times to fix [the defect] which caused a lot of disruption..." (HO6).

There was a mixed view on 'disruption to HBs'. The HOs, BIs, and WPs saw HB disruption as a lesser priority. The BIs and WPs lack of sympathy towards the HB came from the belief that the defects are the HB's own fault. For example, one WP suggested that “...most defects appear to be the result of poor workmanship due a lack of supervision..." (WP1), whereas one BI argued that HBs are mainly production focussed by commenting that "... a lot of the major builders are not really interested in the disruption to a home owner or fixing problems $I[n]$ a timely manner. Production always takes priority..." (BI1). 
[To cite this article: Tony Hopkin, Shu-Ling Lu, Phil Rogers \& Martin Sexton (2017): Key stakeholders' perspectives towards UK new-build housing defects, International Journal of Building Pathology and Adaptation, DOI: 10.1108/IJBPA-06-2016-0012]

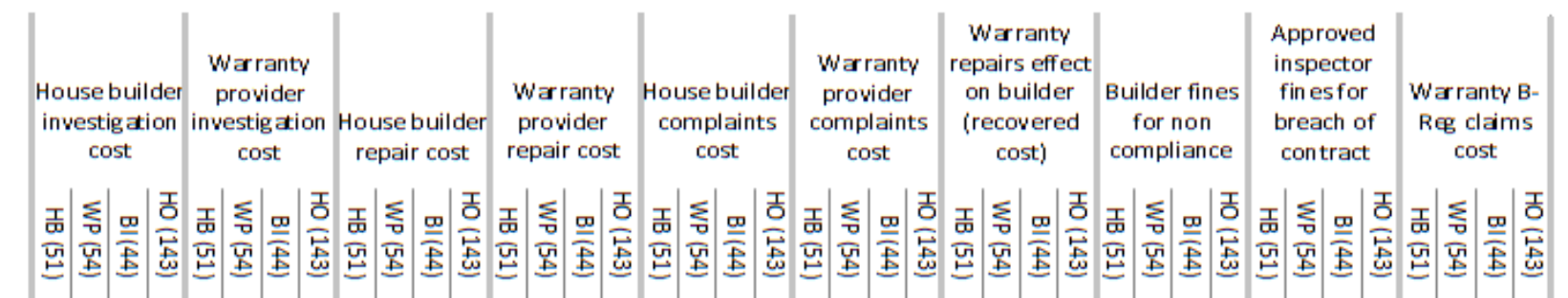

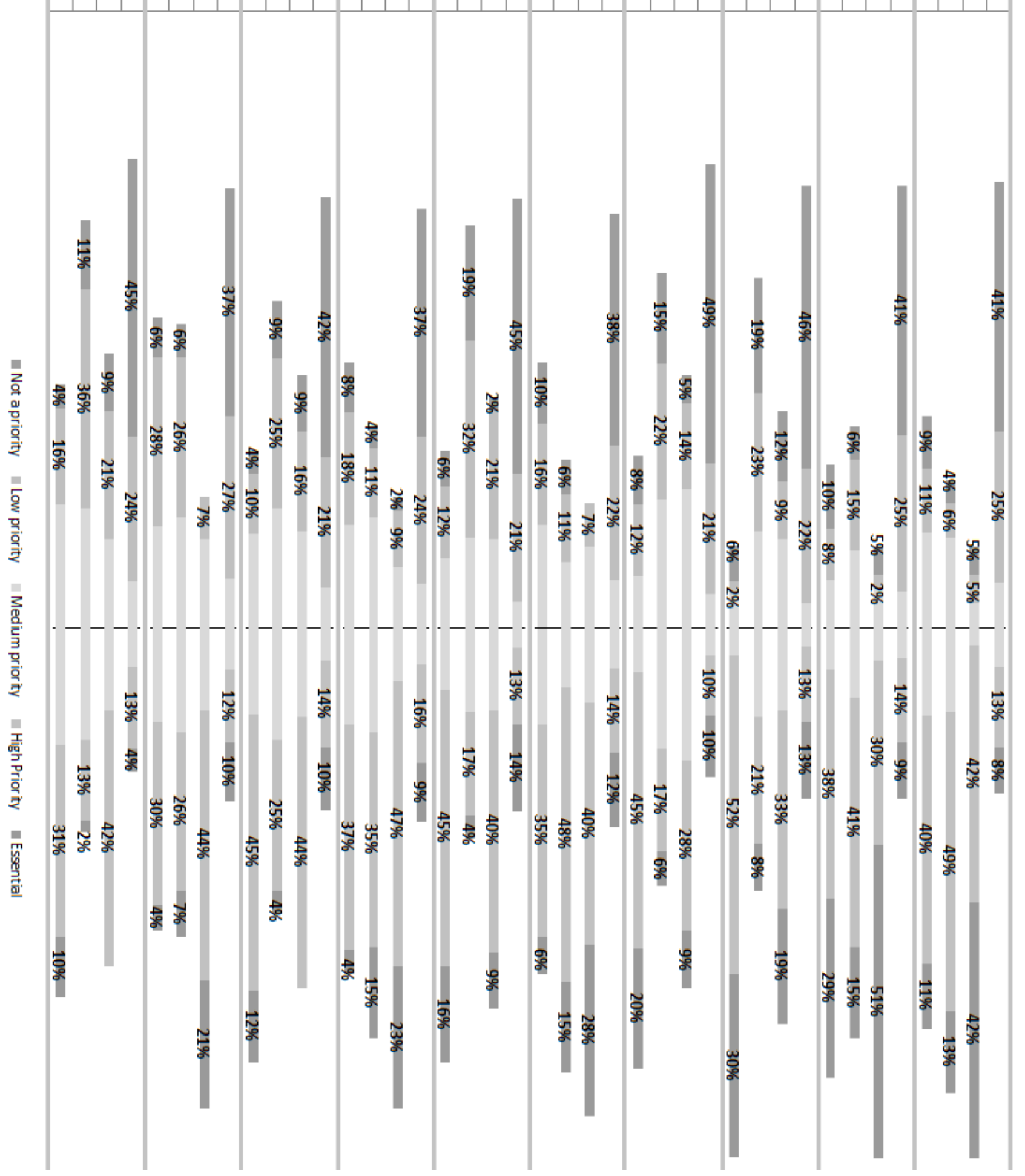

Figure III: Impact of defects on cost priority analysis 
[To cite this article: Tony Hopkin, Shu-Ling Lu, Phil Rogers \& Martin Sexton (2017): Key stakeholders' perspectives towards UK new-build housing defects, International Journal of Building Pathology and Adaptation, DOI: 10.1108/IJBPA-06-2016-0012]

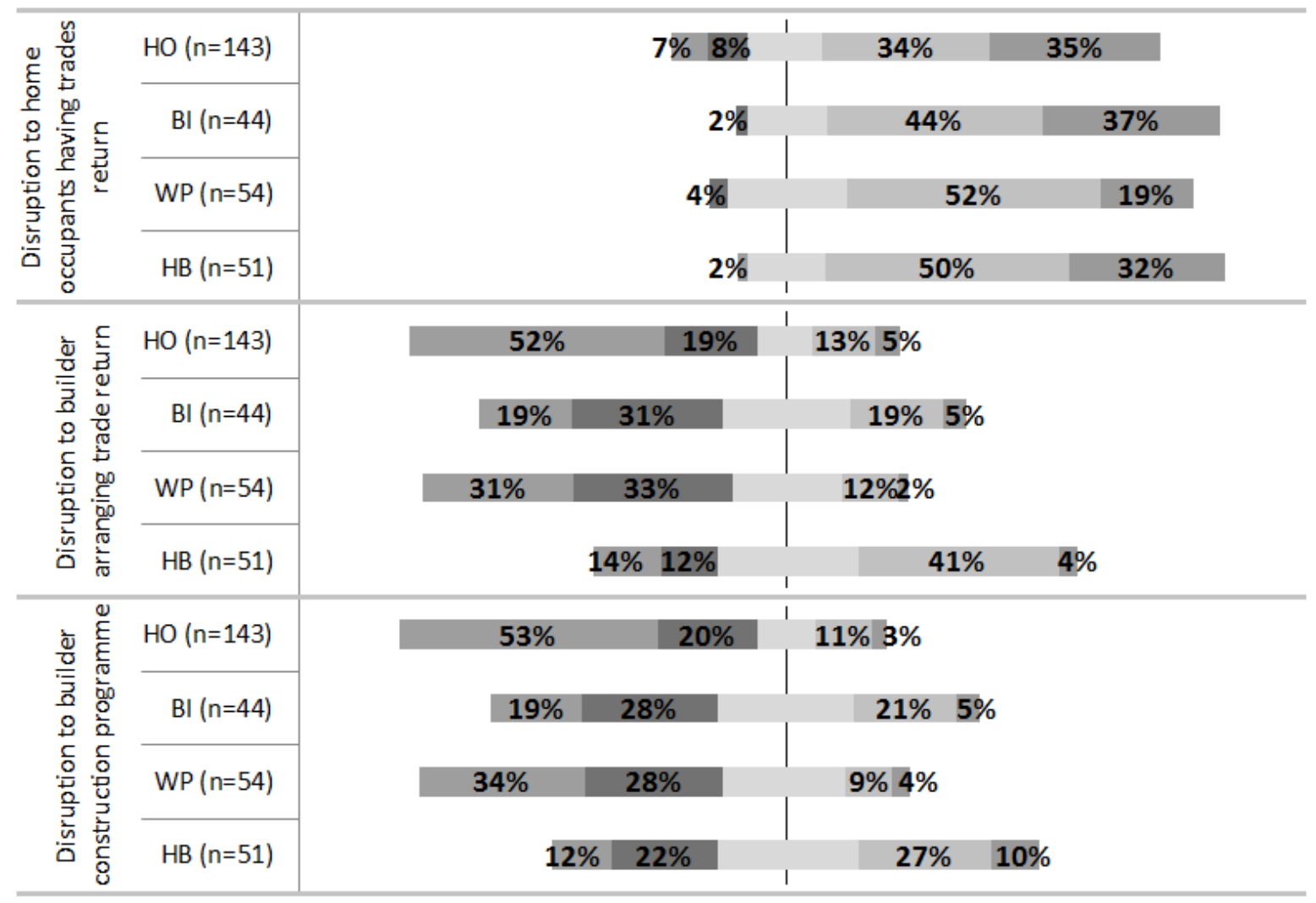

Not a priority $\square$ Low priority Medium priority $\quad$ High Priority Essential

Figure IV: Impact of defects on disruption priority analysis

Through identifying the key stakeholders' priorities towards the impact of defects the survey also uncovered that HOs had a negative perception of the house building industry in general (explaining their self-prioritisation). This negative perception was summarised by one $\mathrm{HO}$ who commented that “...no other industry finds it 'normal' to deliver products with defects and fix them later. Imagine a mobile phone that didn't work, a manual car without a gear stick? The construction industry claims it is different. It isn't. It just has a stranglehold over tight property supply and is so poorly regulated that it isn't subject to competition to raise standards. We are building sub-standard properties that will barely last 20 years..." (HO7).

\section{Additional potential impacts identified from the survey}

The results drawn from the open questions further identified new H\&S, cost, and disruption concerns that defects may present. The new H\&S concerns identified were: the danger defects pose to the general public (suggested by one HO and five WPs); and, the danger defects pose to third parties visiting construction sites (two BIs and two HBs). The new costs incurred uncovered were: the potential costs defects cause HOs, such as time off work or paying a third party for the repair (identified by one HB, three HOs, and one WP); and, the effect defects may have on the home's resale value (two HOs). Finally, the additional disruption implications identified were: the HO not being able to use their property as intended (one $\mathrm{HO}$ ), the need for the $\mathrm{HO}$ to be rehoused during remedial works (one $\mathrm{HO}$ and two WPs); and, the duration of the repair and the need for the HO to take time off of work to allow the $\mathrm{HB}$ access to undertake the repair (four HOs). 


\section{Discussion}

The potential H\&S implications of defects were found to be the main priority to the house building industry in general with $\mathrm{HO}$ disruption seen as the second most important consideration. The high $\mathrm{H} \& \mathrm{~S}$ prioritisation supports the arguments of Baiche et al. (2006) and Ilozor et al. (2004) that there should be focus on defects that may be detrimental to H\&S. This finding, however, is in contrast to the general perception that the house building industry is predominantly financially motivated and cost focussed (Sommerville et al., 2004). The house building industry proclaim to be more focused on reducing defects to limit danger to HOs and workers on-site, along with reducing post-completion disruption than saving money on remediation.

The survey further revealed a level of consensus from the HBs, WPs, and BIs when they placed significant importance on the aspects that affected the HOs. This suggests that the house building industry is customer focussed and indicates a shift in attitude over the last decade since Sommerville et al.'s (2004) recommendation that the construction industry needed to become more customer focused. The three stakeholders' views were however in direct contrast to the HOs' views. The HOs had a sole focus on the impacts that directly affect them and were found to be unconcerned with the effect defects have on the wider industry, stemming from the perception that the industry does not care about HOs, so why should HOs care about the effect defects have on the wider house building industry. Whilst this is unsurprising, the HOs' lack of appreciation for the cost and disruption effects of defects suggests a lack of awareness for the indirect effects defects have on them, in as much as the budgeted cost of defects and the purchase of any warranties for covering defects (by the HB) will be passed onto HOs in an increase to their purchase price. In addition, any defect related delays to the HB's construction programme could delay the home's completion date, and the HO's move-in date, an aspect which only $72 \%$ of HOs were satisfied with when buying a new home (HBF, 2016).

Finally, the seven additional potential impacts of defects identified by the open questions continued to show a contrast between the HOs' perspectives and the remaining house building industry stakeholders' perspectives. The HOs sustained their concentration on the aspects of defects that directly affected them, including the financial cost defects may cause the $\mathrm{HO}$ in requiring a third party to undertake the repair, and the disruption caused by the $\mathrm{HO}$ being required to take time off of work to allow the HB access to their home to undertake repairs. The one notable exception in the HOs was the one HO who identified the danger defects pose to the general public as an additional impact. The house building industry stakeholders again showed a $\mathrm{HO}$ focus in their range of additional impacts, such as potential costs to HOs, or the need to rehouse a HO during repairs.

\section{Conclusions}

There is limited research that has explored which potential impacts of defects are important to the key stakeholders involved in their detection and rectification from construction on-site until the end of the warranty period. The contribution of this research is threefold. First, this research offers fresh insights into how the UK house building industry can benefit from defect reduction, primarily through a reduction in the $\mathrm{H} \& \mathrm{~S}$ problems associated with defects and disruption to home occupants (HOs). HOs are unlikely to welcome disruption resulting from work being carried out incorrectly (BEC, 1991). Therefore the increase in the volume of defects and the additional disruption caused may be a contributing factor to the decline in satisfaction reported in the HBF's 'New Home Customer Satisfaction' surveys (HBF, 2016). Second, the findings shows that there is a clear disconnect between HOs' view of the house building industry's level of customer focus, and the level of customer focus the 
[To cite this article: Tony Hopkin, Shu-Ling Lu, Phil Rogers \& Martin Sexton (2017): Key stakeholders' perspectives towards UK new-build housing defects, International Journal of Building Pathology and Adaptation, DOI: 10.1108/IJBPA-06-2016-0012]

house building industry claim to have. Finally, this research can complement existing defect scholarship to help researchers identify what types of defects are important (based upon the level of disruption they cause and H\&S concerns they pose) and subsequently which defects should be focussed on. Further, research into house builders' (HBs') defect reduction attempts in practice found that they sought to reduce the highest frequency defect types experienced - albeit with limited success (Hopkin et al., 2016). The findings from this research could offer the HBs an alternative approach to determine which defects should be targeted.

The key implication for practice is that the HBs need to address the negative perception the HOs have of the HBs, i.e. HBs are not customer focussed or interested in providing HOs new homes they can be satisfied with. In order to address this, HBs should build up a profile of defects that occur within their build stock taking note of the defects that are identified during construction, reported by HOs during the builder's liability period, and defects that result in claims during the warranty period. Then HBs should review the defect profiles and prioritise defects that pose H\&S concerns and cause disruption to HOs for targeted defect reduction in further developments. Whilst in an ideal world new homes should be defect free, in reality defects still exist. This new approach to targeted defect reduction can help reduce highly disruptive and unsafe defects, and help improve the HOs' image of HBs and the house building industry as a whole.

\section{Acknowledgements}

The authors thank National House Building Council and the Engineering and Physical Sciences Research Council (grant: EP/G037787/1) for their funding and support.

\section{References}

ACAI: The Association of Consultant Approved Inspectors (2013) Contract for the appointment of an approved inspector, CIC/AppInsp, $2^{\text {nd }}$ eds, Construction Industry Council, London, UK, pp. $1-14$.

Atkinson, A. (2002) "The pathology of building defects: a human error approach", Engineering, Construction and Architectural Management, Vol. 9 No. 1, pp. 53-61.

Auchterlounie, T. (2009) "Recurring quality issues in the UK private house building industry", Structural Survey, Vol. 27 No. 3, pp. 241-251.

Baiche, B., Walliman, N. and Ogden, R. (2006) "Compliance with building regulations in England and Wales”, Structural Survey, Vol. 24 No. 4, pp. 279-299.

Barker, K. (2004) Review of Housing Supply. Her Majesty's Stationery Office, Norwich, UK, pp. 1158.

BEC: Building Employers Confederation (1991) Right first time, quality management for the smaller builder, Building Employers Confederation, London, UK, pp. 1-52.

CIC: Construction Industry Council (2010) Liability Briefing, CML Certificates, Construction Industry Council, London, UK, pp. 1-4.

CIC: Construction Industry Council (2014) "Insurance and Warranties", available at: http://bit.ly/1NkkoaS (accessed 24 September 2014).

CITB: Construction Industry Training Board (2015) Industry Insights: Construction Skills Network, Blueprint for construction 2015-2019, CITB, Norfolk, UK, pp. 1-47.

Craig, N. (2007) The prevailing trends of defects and snagging in new homes in the UK, unpublished $\mathrm{PhD}$ thesis, Glasgow Caledonian University, Glasgow, UK. 
[To cite this article: Tony Hopkin, Shu-Ling Lu, Phil Rogers \& Martin Sexton (2017): Key stakeholders' perspectives towards UK new-build housing defects, International Journal of Building Pathology and Adaptation, DOI: 10.1108/IJBPA-06-2016-0012]

Davey, C., McDonald, J., Lowe, D., Duff, R., Powell, J. A. and Powell, J. E. (2006) "Defects liability management by design", Building Research and Information, Vol. 34 No. 2, pp. 145-153.

DCLG: Department for Communities and Local Government (2012) Proposed changes to the building control system, Department for Communities and Local Government, London, UK, pp. $1-41$.

DCLG: Department for Communities and Local Government (2016) "Live tables on house building", available at: http://bit.ly/234uxQc (accessed 28 March 2016).

Forcada, N., Macarulla, M., Gangolells, M. and Casals, M. (2016) "Handover defects: comparison of construction and post-handover housing defects", Building Research and Information, Vol. 44 No. 3, pp. 279-288.

FOS: Financial Ombudsman Service (2013) Annual review of consumer complaints about: insurance, credit, banking, savings and investments, Financial Ombudsman Service, London, UK, pp. 1174.

Georgiou, J., Love, P. and Smith, J. (1999) “A comparison of defects in houses constructed by owners and registered builders in the Australian State of Victoria”, Structural Survey, Vol. 17 No. 3, pp. 160-169.

HBF: Home Builders Federation (2016) National New Home Customer Satisfaction Survey, Home Builders Federation, London, UK, pp. 1-4.

Heiberger, R. and Robbins, N. (2014) "Design of diverging stacked bar charts for Likert scales and other applications", Journal of statistical software, Vol. 57 No. 5, pp. 1-32.

HMSO: Her Majesty’s Stationery Office (1984) Building Act, Her Majesty’s Stationery Office, London, UK, pp. 1-8.

HM Treasury (2016) “Autumn Statement 2016”, available at: http://bit.ly/2gKyyry (accessed 29 November 2016).

Hopkin, T., Lu, S., Rogers, P. and Sexton, M. (2016) "Detecting defects in the UK new-build housing sector: a learning perspective”, Construction Management and Economics, Vol. 34 No. 1, pp. $35-45$.

HouseMark (2012) Value for money in responsive and void repairs, HouseMark, Coventry, UK, pp.124.

Ilozor, B., Okoroh, M., Egbu, C. and Archicentre. (2004) "Understanding residential house defects in Australia from the State of Victoria”, Building and Environment, Vol. 39 No. 3, pp. 327-337.

Joreskob, K and Moustaki, I (2001) "Factor analysis of ordinal variables: a comparison of three approaches", Multivariate Behavioral Research, Vol. 36 No. 3, pp. 347-387.

Josephson, P. and Hammarlund, Y. (1999) "The causes and costs of defects in construction: A study of seven building projects", Automation in Construction, Vol. 8 No. 6, pp. 681-687.

Love, P. and Li, H. (2000) "Quantifying the causes and costs of rework in construction", Construction Management and Economics, Vol. 18 No. 4, pp. 479-490.

Macarulla, M., Forcada, N., Casals, M., Gangolells, M., Fuertes, A. and Roca, X. (2013) "Standardizing Housing Defects: Classification, Validation, and Benefits", Journal of Construction Engineering and Management, Vol. 139 No. 8, pp. 968-976.

Mills, A., Love, P. and Williams, P. (2009) "Defect Costs in Residential Construction", Journal of Construction Engineering and Management, Vol. 135 No. 1, pp. 12-16.

NAO: National Audit Office (2007) Homebuilding: Measuring Construction Performance, National Audit Office, London, UK, pp. 1-21.

NHBC: National House Building Council. (2011) Technical Extra: Issue 01, National House Building Council, Milton Keynes, UK, pp. 1-28. 
[To cite this article: Tony Hopkin, Shu-Ling Lu, Phil Rogers \& Martin Sexton (2017): Key stakeholders' perspectives towards UK new-build housing defects, International Journal of Building Pathology and Adaptation, DOI: 10.1108/IJBPA-06-2016-0012]

NHBC: National House Building Council (2012) Buildmark, National House Building Council, Milton Keynes, UK, pp. 1-28.

NHBC: National House Building Council (2015) Annual Report and Accounts 2014/15, National House Building Council, Milton Keynes, UK, pp. 1-116.

Parliament (2016) “Housing supply in 2015-2020", available at: http://bit.ly/2fxLAIg (accessed 29 November 2016).

Premier Guarantee (2013) New home Warranty, Premier Guarantee, Wirral, UK, pp. 1-16.

Rosenfeld, Y. (2009) "Cost of quality versus cost of non-quality in construction: the crucial balance", Construction Management and Economics, Vol. 27 No. 2, pp. 107-117.

Rosenthal, J. (2012) Statistics and data interpretation for social work, Springer Publishing Company, New York, NY.

Sommerville, J., Craig, N. and Bowden, S. (2004) "The standardisation of construction snagging", Structural Survey, Vol. 25 No. 5, pp. 251-258.

Sommerville, J. and McCosh, J. (2006) "Defects in new homes: an analysis of data on 1,696 new UK houses", Structural Survey, Vol. 24 No. 1, pp. 6-21.

Sommerville, J (2007) "Defects and rework in new build: an analysis of the phenomenon and drivers", Structural Survey, Vol. 25 No. 5, pp. 391-407.

Wilson, W. and Rhodes, C. (2016) New-build housing defects - issues and solutions, House of Commons Library, London, UK, pp.1-19. 